\title{
Iteration Method for Simultaneous Estimation of Vertical Profiles of Air Temperature and Water Vapor with AQUA/AIRS Data
}

\author{
Kohei Arai \\ Department of Information Science \\ Saga University \\ Saga City, Japan
}

\begin{abstract}
Iteration method for simultaneous estimation of vertical profiles of air temperature and water vapor with the high spectral resolution of sounder of AQUA/AIRS data is proposed. Through a sensitivity analysis based on the proposed method for the several atmospheric models simulated by MODTRAN, it is found that the proposed method is superior to the conventional method by $41.4 \%$ for air temperature profile and by $\mathbf{8 8 . 9 \%}$ for relative humidity profile.
\end{abstract}

Keywords-Inversion; tropopause; AQUA; AIRS; Air temperature; sounder; MODTRAN

\section{INTRODUCTION}

Atmospheric sounding can be improved by using the high spectral resolution of sounder, such as AQUA ${ }^{1} / \mathrm{AIRS}^{2}$ onboard AQUA satellite, IASI $^{3}$, instead of HIRS ${ }^{4}$, TOVS ${ }^{5}$ used in the past [1]. Estimation of air-temperature profile with AQUA/AIRS data on the tropospheric boundary is tried [2]. Meanwhile, water vapor and air-temperature profile estimation with AIRS data based on Levenberg-Marquadt is proposed [3]. On the other hand, a sensitivity analysis for air temperature profile estimation method around the tropopause using simulated AQUA/AIRS data is carried out [4]. Also, a method for water vapor profile retrievals by means of minimizing difference between estimated and brightness temperature derived from AIRS data and radiative transfer model is proposed [5].

These sensors have large number of channels, and have large amount of atmospheric sounding information in the measurement data. However, for the retrieval of air temperature profile, it is not practical nor an advantage to use all spectral points. Therefore, it is important for this work to eliminate those redundant channels whose information does not add to the final retrieval accuracy and even before for the sake of efficiency, those channels potentially contaminated by solar radiation or significantly affected by other gases (not required for temperature profiling). Because of the influence due to the

\footnotetext{
${ }^{1}$ https://aqua.nasa.gov/

${ }^{2}$ https://ja.wikipedia.org/wiki/Aqua_(\%E4\%BA\%BA\%E5\%B7\%A5\%E8 $\% \mathrm{~A} 1 \% 9 \mathrm{~B} \% \mathrm{E} 6 \% 98 \% 9 \mathrm{~F})$

${ }^{3}$ https://www.eumetsat.int/website/home/Satellites/CurrentSatellites/Meto $\mathrm{p} /$ MetopDesign/IASI/index.html

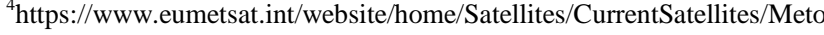
p/MetopDesign/HIRS/index.html

${ }^{5}$ https://eosweb.larc.nasa.gov/content/tovs
}

thermal radiation from earth's surface and the sharp variation of air temperature at around tropopause ${ }^{6}$, on the other hand, the retrieval accuracies of air temperature at the surface and around the tropopause are not so high $(\sim 4 \mathrm{~K})$ in the previous works ${ }^{7}$ even using the high spectral resolution of sounder. One of the factors for this result is caught by insufficient channels selection. Some of redundant channels have to be removed from the air temperature profile estimation.

In this paper, a simultaneous estimation of vertical profiles of air temperature and water vapor with AQUA/AIRS data is proposed. There is a relation between vertical files of air temperature and water vapor. For instance, when sea surface temperature is raised then water vapor in the atmosphere is increased accordingly. Vertical profiles estimation accuracies can be improved if the relation is used in the estimation method. In order to confirm the effect of simultaneous estimation, MODTRAN ${ }^{8}$ (Moderate Resolution Transmittance Code) is used for simulation.

The following section describes the theoretical background and related research works followed by the proposed method. Then, sensitivity analysis is described followed by simulation result. Finally, conclusion is described with some discussions and future research work.

\section{PRoposed Method AND RELATED Studies}

\section{A. Theoretical Background and Related Studies}

The general forward model of the equation mapping the state (atmospheric profile) into measurement space (satellitemeasured radiance or brightness temperature spectrum) is expressed as follows [6]:

$$
y=F(x)+\varepsilon
$$

Where, $y$ is the measurement vector, $F(x)$ is the forward model operator for a given state $x$, and $\varepsilon$ is the measurement error.

The measurement error characteristics should be known, and the measurements $y$ should be corrected before using them

\footnotetext{
${ }^{6}$ https://en.wikipedia.org/wiki/Tropopause

${ }^{7} \mathrm{https}: / / c$ limatedataguide.ucar.edu/climate-data/airs-and-amsutropospheric-air-temperature-and-specific-humidity

${ }^{8} \mathrm{http}: / /$ modtran.spectral.com/
} 
in the retrieval. Given a reasonable air temperature profile for $x$, equation (1) can be approximately linearized as follows:

$$
y-y_{0}=K_{0}\left(x-x_{0}\right)
$$

Where, $K_{0}=\partial F(x) / \partial x$ is the weight function matrix with respect to $x_{0}$, and $x_{0}$ is suitable reference state.

For the retrieval of air temperature profile from brightness temperature measurements $y$, the inverse problem associated with (1) is proposed by the concept of Bayesian optimal estimation ${ }^{9}$ described by Rodgers [6] as follows:

$$
x=x_{a}+\left(K^{T} S_{\varepsilon}^{-1} K+S_{a}^{-1}\right)^{-1} K^{T} S_{\varepsilon}^{-1}\left(y-F\left(x_{a}\right)\right)
$$

Where, $x_{a}$ is a priori profile for air temperature, $S_{a}$ is the a priori error covariance matrix and $S_{\varepsilon}$ is the measurement error covariance matrix. $K$ is the weighting matrix. $F\left(x_{a}\right)$ are the brightness temperatures from simulation with respect to $x_{a}$. Considered the problem is nonlinear, an iterative optimal estimation is selected as follows:

$$
x_{i+1}=x_{a}+\left(K_{i}^{T} S_{\varepsilon}^{-1} K_{i}+S_{a}^{-1}\right)^{-1} K_{i}^{T} S_{\varepsilon}^{-1}\left(\left(y-F\left(x_{i}\right)\right)+K_{i}\left(x_{i}-x_{a}\right)\right)
$$

Where, subscript $i$ is the iteration index. The optimum can be obtained only by $2 \sim 4$ iterations because the problem is moderately nonlinear. This is the conventional method for vertical profile estimation with thermal infrared sounder data. Namely, vertical profile of air temperature is estimated separately with that of water vapor, independently.

With respect to high spectral resolution of sounder, thousands of measurements data are obtained in accordance with the channels. Air temperature profile $(x)$ to only a few dozens of air temperatures at different altitude levels is usually dispersed. It is not practical nor an advantage to use all spectral points. Some of them, which information are not required for temperature profiling, even decrease the retrieval accuracies. Thus, it is important to sufficiently select channels suitable for the retrieval of air temperature profile.

\section{B. Principle of Vertical Profile of Air Temperature and Water Vapor Estimations}

Fig. 1 is spectral absorption characteristic in thermal IR region. The region $620 \sim 740 \mathrm{~cm}^{-1} \mathrm{CO}_{2}$ absorption bands can be used for the retrieval of air temperature profile. More accurate reduction of the abundant channels is adopted the Information Content (IC) measure ${ }^{10}$ as described by Rodger [7].

It, however, generally used in pre-process for the inverse scheme. It also means that the channels cannot be changed as the inverse scheme described as above to retrieve the air temperature profile after the pre-process for channels selection is performed. From the line-by-line computation for absorbance coefficient, on the other hand, absorbance

\footnotetext{
${ }^{9}$ https://en.wikipedia.org/wiki/Bayesian_optimization

${ }^{10} \mathrm{https} / / /$ en.wikipedia.org/wiki/Information_criterion
}

coefficient is not only depended on the spectrum, but also associated with the air temperature [8]. Meanwhile, it is nonlinear between the absorbance coefficient and the air temperature. One channel which information can add best to the retrieval accuracies at the certain temperature may not be at the other temperature. This relation becomes more significant at around the tropopause of which the sharp equatorial structure with the sharp temperature changes. One of the factors, thus, that result in the difficulty to improve the retrieval accuracies of air temperature at around tropopause is that the channels cannot change in the inverse scheme with respect to the different retrieval temperature profile.

As mentioned before, there is cross link between air temperature and water vapor. Therefore, it may be possible to improve estimation accuracy by using the relation. Iteration method for simultaneous estimation of air temperature and water vapor profiles is then proposed.

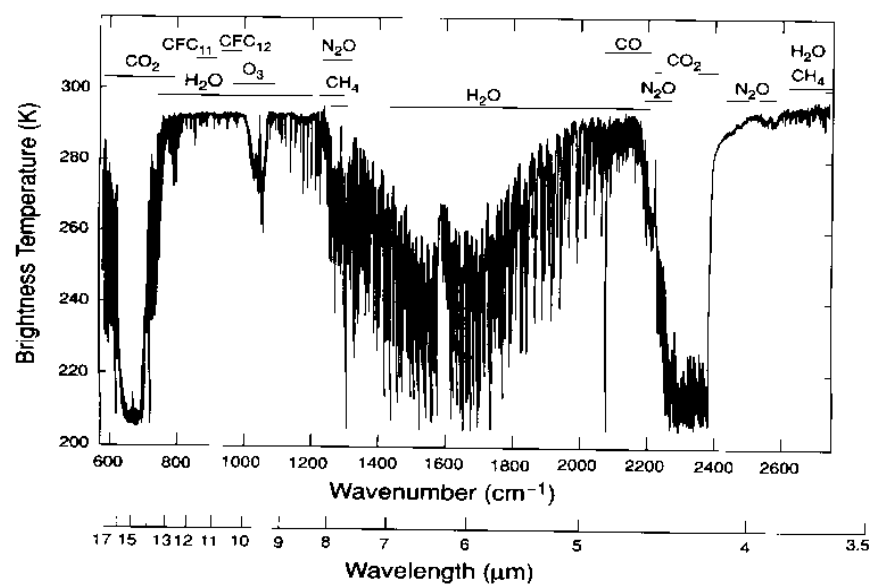

(a) Overall

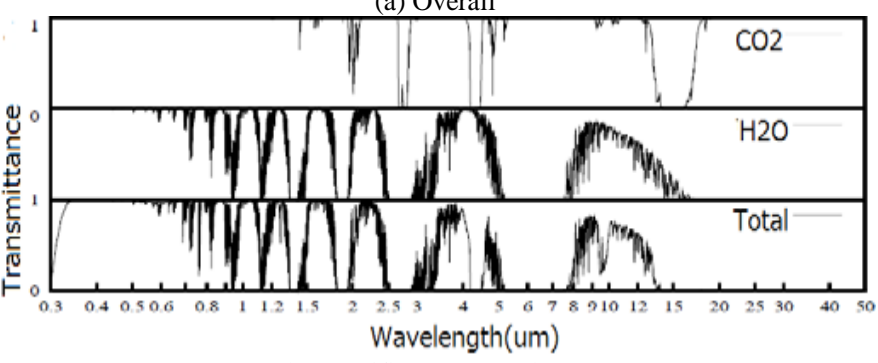

(b) Specific to $\mathrm{CO}_{2}$ and $\mathrm{H}_{2} \mathrm{O}$

Fig. 1. Spectral absorption characteristic in thermal IR region.

\section{PROPOSED METHOD}

\section{A. Weighting Function}

The weighting function is expressed as follows:

$$
K=\partial T_{b} / \partial T
$$

Where, $T_{b}$ denotes brightness temperature while $T$ denotes air temperature. At sensor brightness temperature, $\mathrm{Tb}$ and air temperature, $\mathrm{T}$ can be estimated with MODTRAN. Fig. 2(a) shows an example of the input parameters of MODTRAN while Fig. 2(b) shows the output of $\mathrm{Tb}$ and $\mathrm{T}$ come out from MODTRAN. 


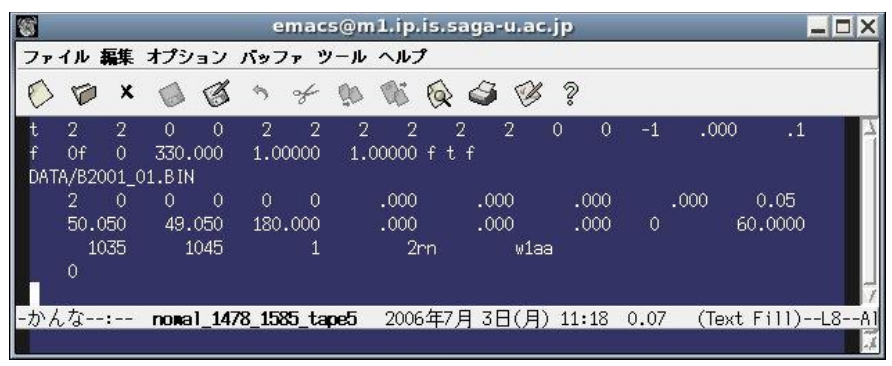

(a) Input

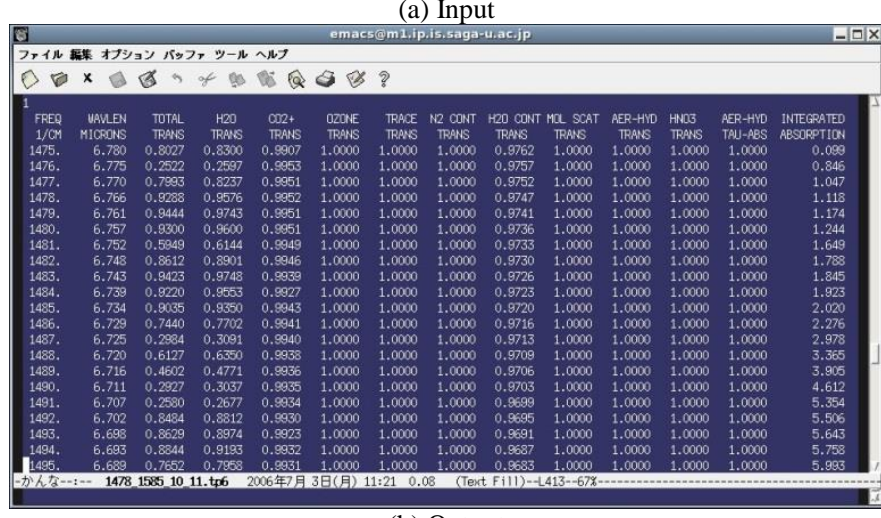

(b) Output

Fig. 2. Example of input parameters and output of MODTRAN.

Thus, atmospheric transparency can be estimated with MODTRAN followed by weighting function because the derivative of the transparency is weighting function. Fig. 3 shows an example of estimated atmospheric transparency and weighting function.

If the input parameter of certain wave number is selected for MODTRAN, then weighting function can be estimated accordingly as shown in Fig. 4.
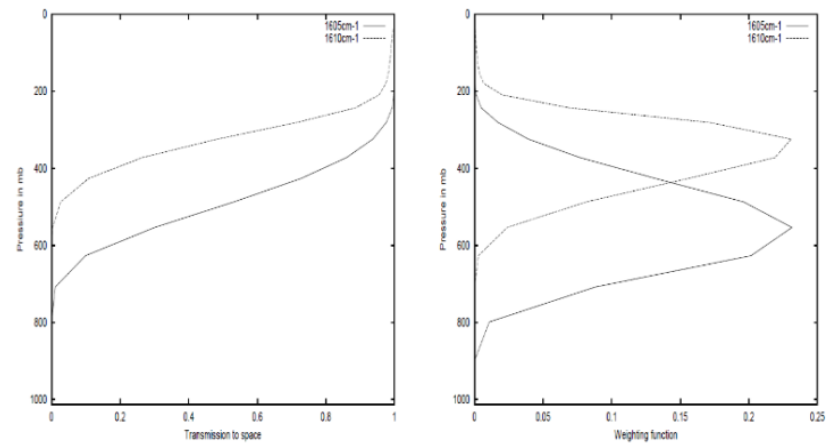

Fig. 3. Example of estimated atmospheric transparency and weighting function.

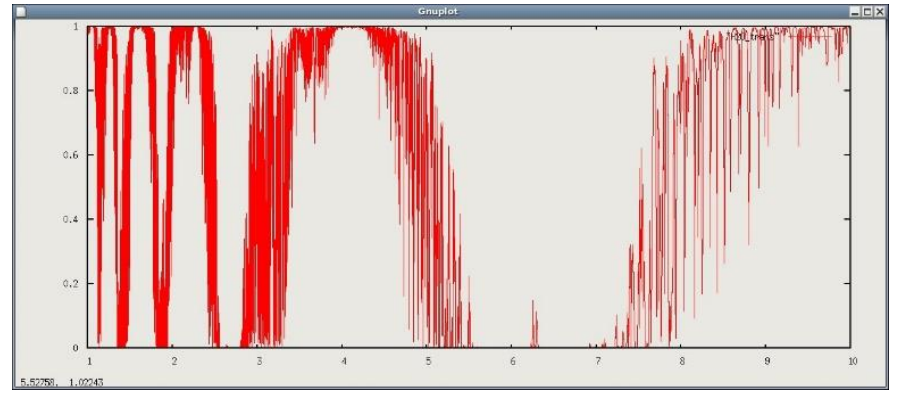

Fig. 4. Example of atmospheric transparency.

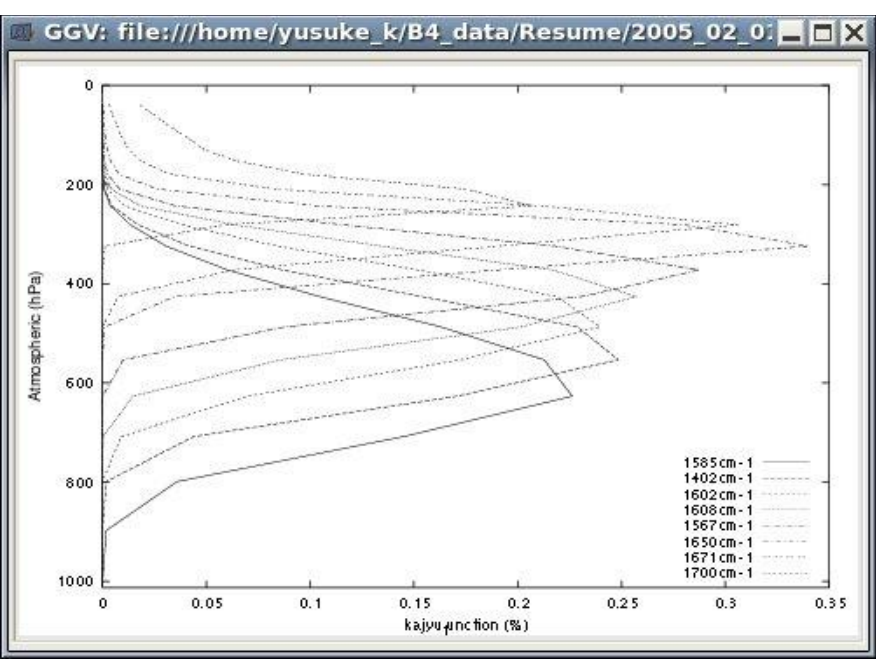

Fig. 5. Weighting functions for the wave number, 1478、1483、1508、 1514、1519、1541、1544、1558、1585 $\mathrm{cm}^{-1}$

When the wave number of 1478、1483、1508、1514、 1519、1541、1544、1558、1585 $\mathrm{cm}^{-1}$ is selected, then the weighting functions are estimated as shown in Fig. 5.

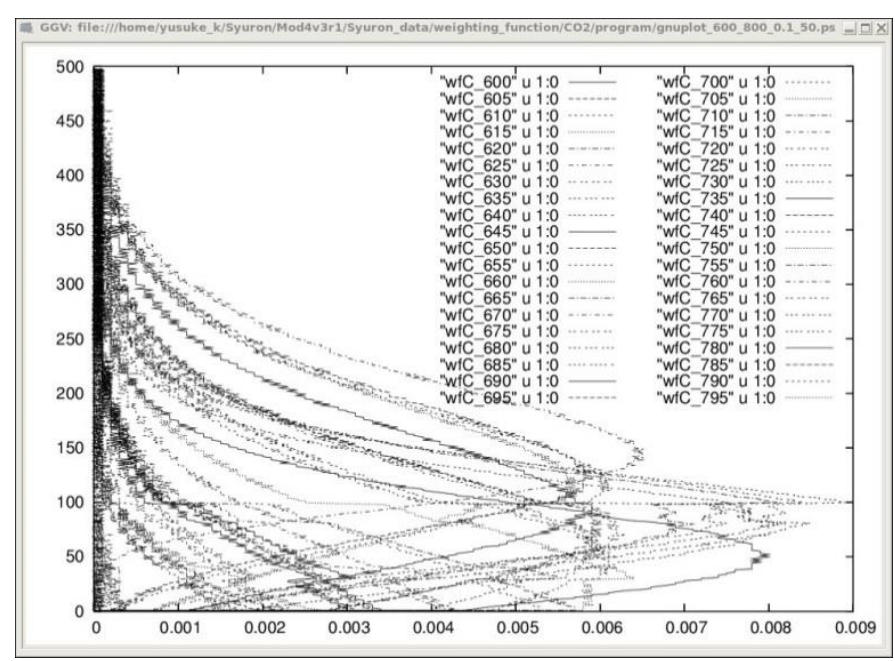

(a) Water vapor

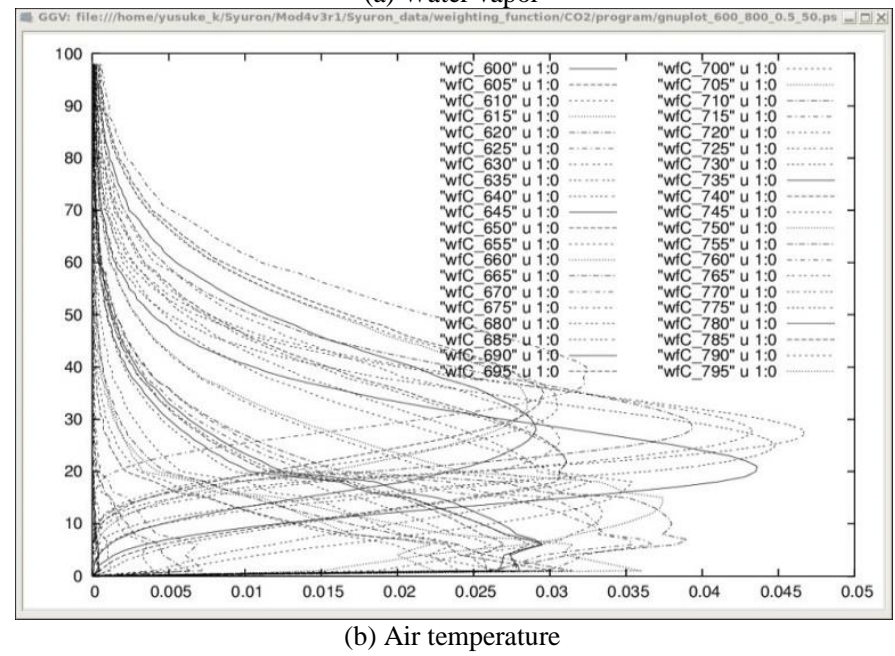

Fig. 6. Finding most appropriate wave number for estimation of water vapor and air temperature profiles. 


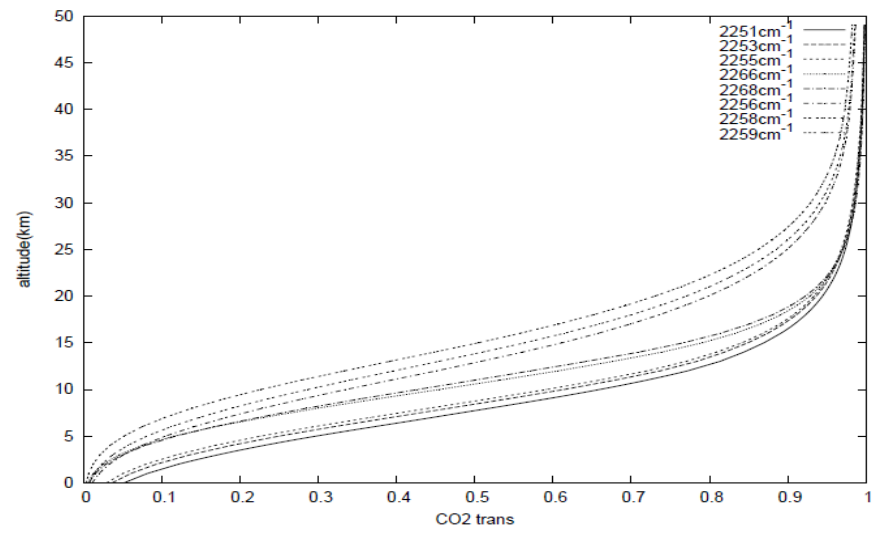

(a) Transparency

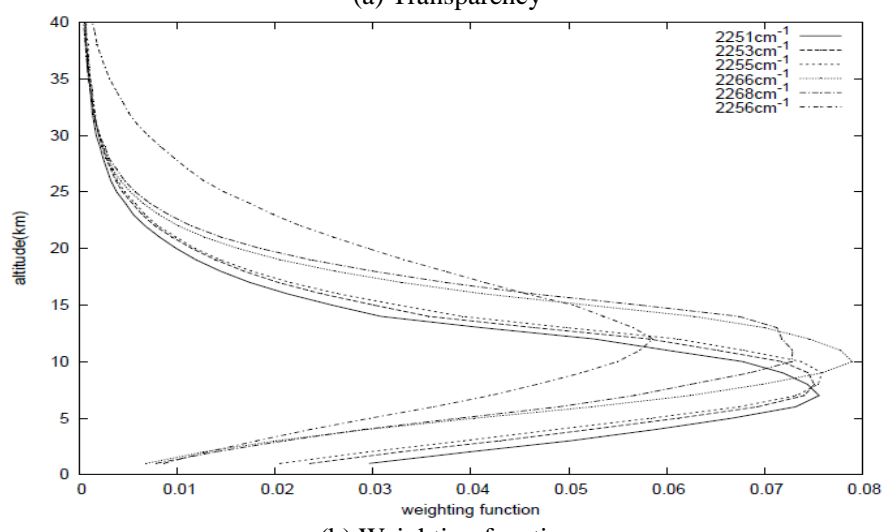

(b) Weighting function

Fig. 7. Relation between $\mathrm{CO}_{2}$ transparency and altitude while weighting function of $\mathrm{CO}_{2}$.

This is the same thing for estimation of weighting functions at arbitrary wave numbers as shown in Fig. 6. When the wave number is selected at the water vapor absorption bands, then weighting function for water vapor profile estimation can be selected as shown in Fig. 6(a). That is the same thing for air temperature profile estimation. When the wave number is selected at the air temperature absorption bands, then weighting function for air temperature profile estimation can be selected as shown in Fig. 6(b).

As shown in Fig. 4, atmospheric transparency due to carbon dioxide of air temperature is calculated with MODTRAN. Fig. 7(a) shows the relation between $\mathrm{CO}_{2}$ transparency and altitude while weighting function of $\mathrm{CO}_{2}$ is shown in Fig. 7(b).

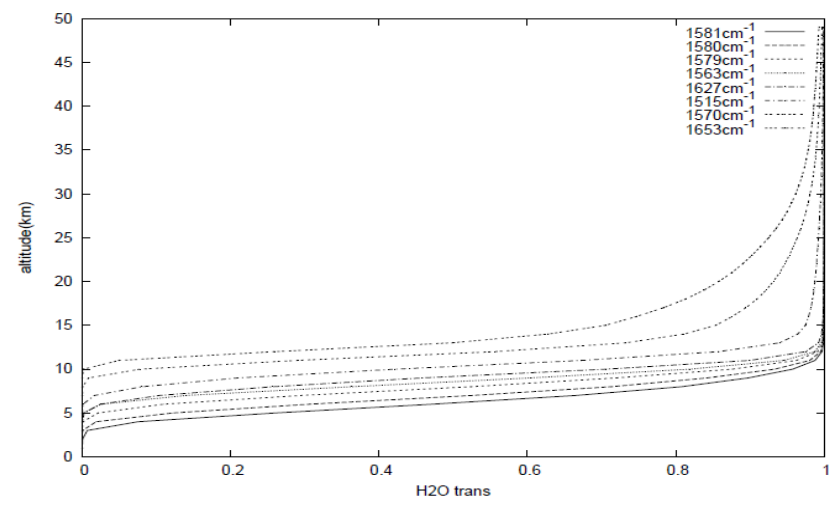

(a) Transparency

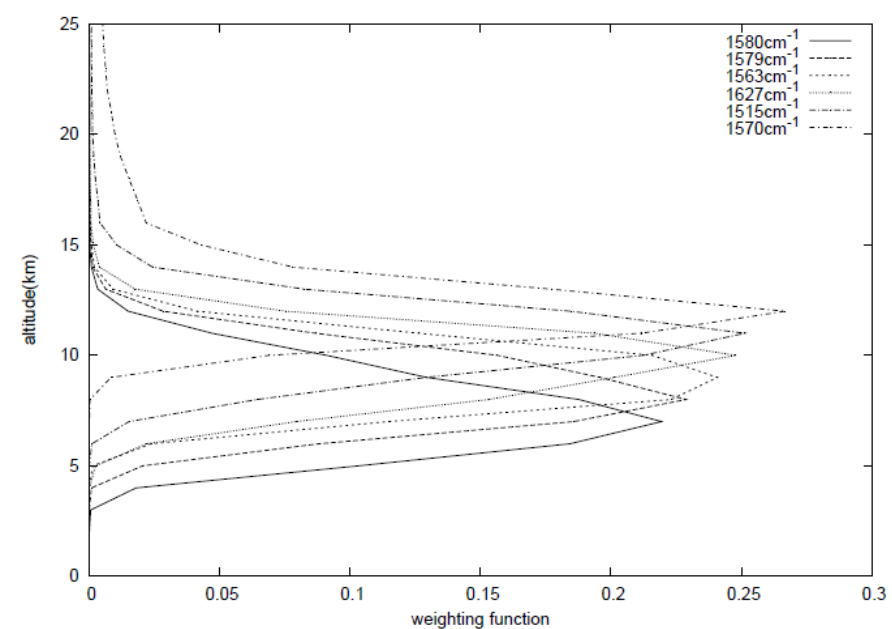

(b) Weighting function

Fig. 8. Relation between $\mathrm{H}_{2} \mathrm{O}$ transparency and altitude while weighting function of $\mathrm{H}_{2} \mathrm{O}$.

On the other hand, Fig. 8(a) shows the relation between $\mathrm{H}_{2} \mathrm{O}$ transparency and altitude while weighting function of $\mathrm{H}_{2} \mathrm{O}$ is shown in Fig. 8(b).

\section{B. Relation between Water Vapor and Air Temperature}

It is possible to calculate air temperature and precipitable water, or water vapor content in the atmosphere by using MODTRAN. Fig. 9(a) shows the relation for Mid-Latitude Summer in day time model while Fig. 9(b) shows the relation for Mid-Latitude Winter in night time model, respectively.

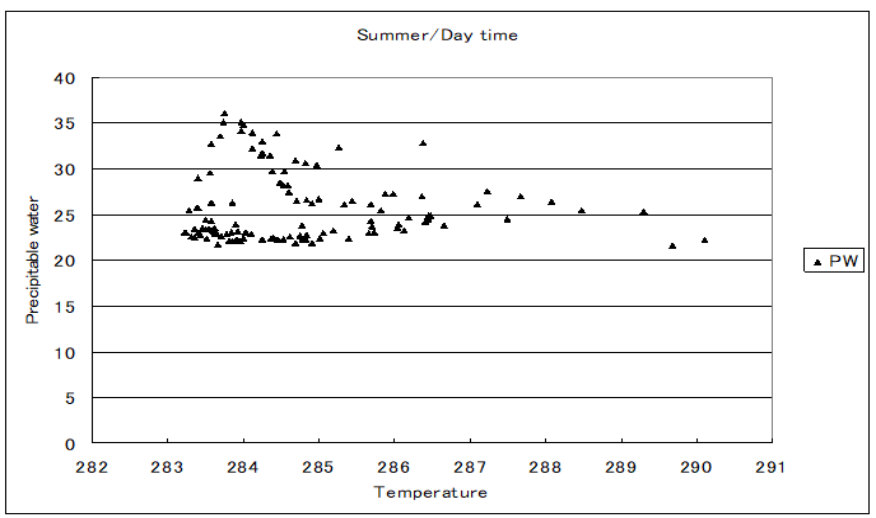

(a) Mid-latitude summer (day time)

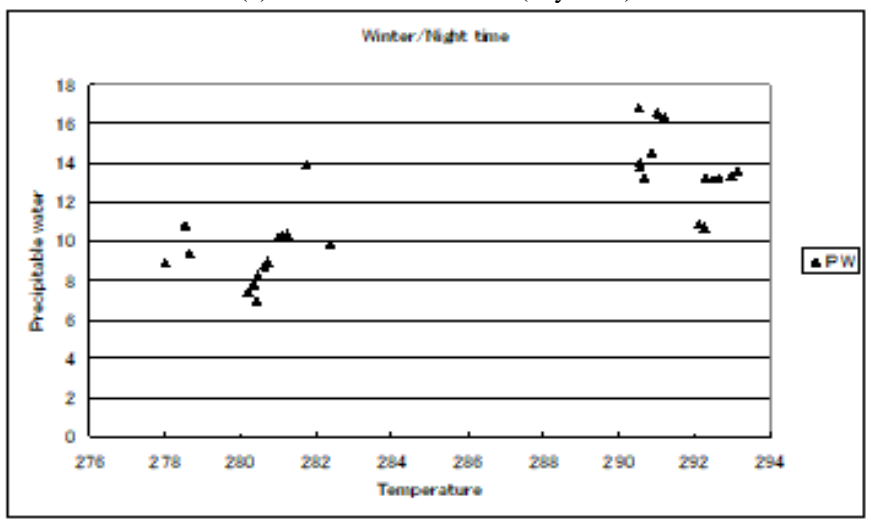

(b) Mid-latitude winter (night time)

Fig. 9. Relation between air temperature and water vapor. 


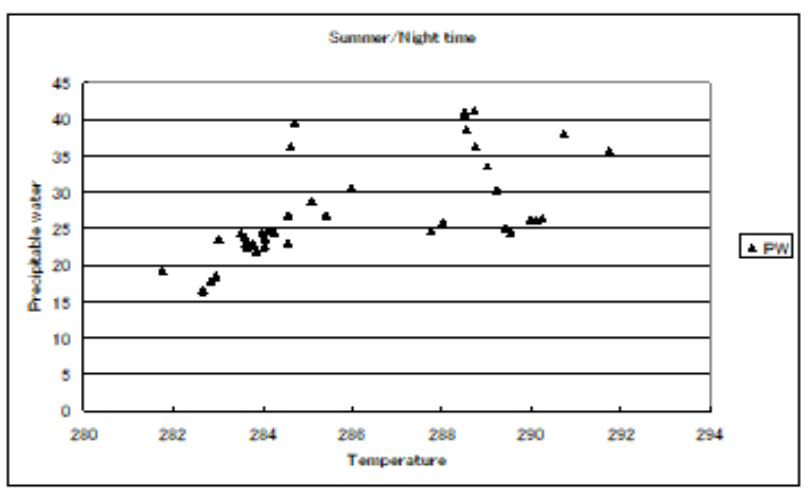

(a) Mid-latitude summer (night time)

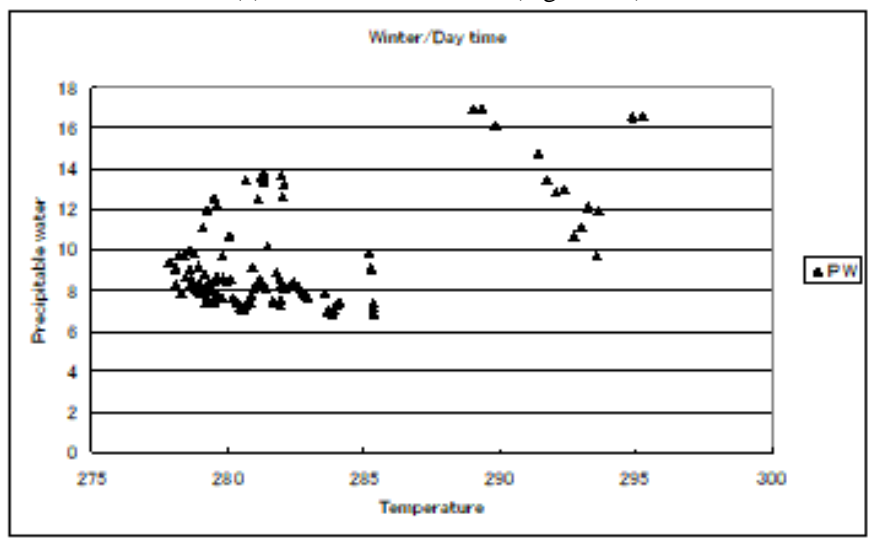

(b) Mid-latitude winter (day time)

Fig. 10. Relation between air temperature and water vapor.

Meanwhile, Fig. 10(a) shows the relation for Mid-Latitude Summer in night time model while Fig. 10(b) shows the relation for Mid-Latitude Winter in day time model, respectively.

As shown in Fig. 9 and 10, it is obvious that there is relation between air temperature and water vapor. Therefore, it may be possible to improve estimation accuracy by using the relation. Iteration method for simultaneous estimation of air temperature and water vapor profiles is then proposed.

The proposed method is an iteration method. Firstly, initial value of air temperature and relative humidity is selected. Then, air temperature profile is estimated with the initial value of relative humidity by the conventional method. After that, relative humidity is estimated with the estimated air temperature profile just mentioned above by the conventional method. These processes are repeated iteratively until the residual error reaches to the convergence radius.

\section{ACCURACY Evaluation}

\section{A. Preliminary Results}

When the wave number of $1478 、 1483 、 1508 、 1514$ 、 1519、1541、1544、1558、1585 $\mathrm{cm}^{-1}$ is selected, then the weighting functions are estimated as shown in Fig. 5. Fig. 11 shows water vapor (Relative Humidity) profile estimated with the conventional method. In the figure, solid line shows MODTRAN derived profile while dotted line shows the estimated profile with the conventional method. There are some differences as shown in Fig. 11 clearly.

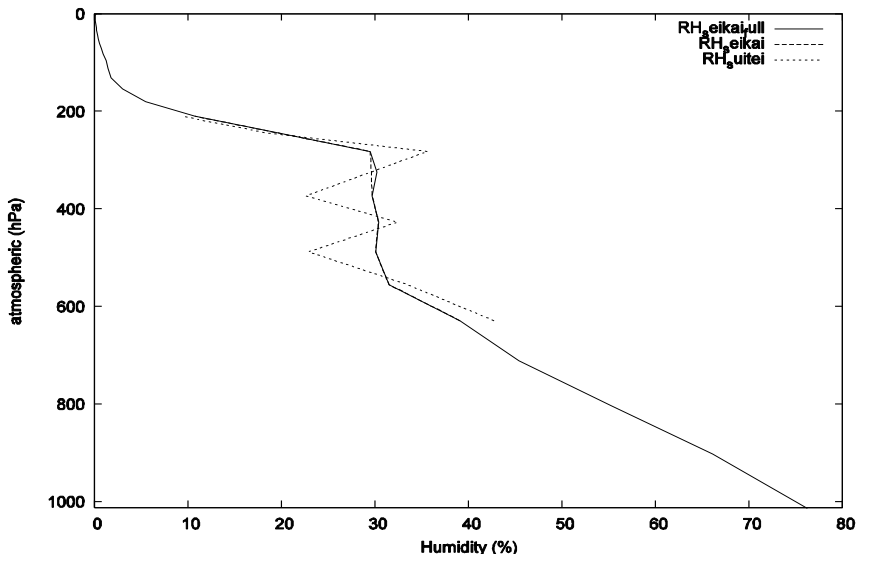

Fig. 11. Estimated water vapor profile.

TABLE I. EXAMPLE OF THE ESTIMATION ACCURACY EVALUATION RESUlT FOR RELATIVE HUMIDITY PROFILE FOR MID-LATITUDE SUMMER MODEL

\begin{tabular}{|l|l|l|l|l|}
\hline $\begin{array}{c}\text { Wave number } \\
\mathbf{c m}\end{array}$ & $\begin{array}{l}\text { Peak } \\
(\mathbf{k m})\end{array}$ & $\begin{array}{l}\text { Correct Rh } \\
(\%)\end{array}$ & $\begin{array}{l}\text { Estimated R } \\
\mathbf{h}(\%)\end{array}$ & Diff. \\
\hline 1585 & 4 & 39.049 & 42.640 & 3.591 \\
\hline 1402 & 5 & 31.417 & 33.380 & 1.963 \\
\hline 1602 & 6 & 29.980 & 22.828 & 7.152 \\
\hline 1608 & 7 & 30.310 & 32.359 & 2.049 \\
\hline 1567 & 8 & 29.630 & 22.573 & 7.057 \\
\hline 1650 & 10 & 29.440 & 35.553 & 6.113 \\
\hline 1671 & 11 & 19.480 & 18.332 & 1.148 \\
\hline 1700 & 12 & 10.694 & 9.329 & 1.365 \\
\hline
\end{tabular}

Estimation accuracy is calculated through comparisons between the estimated relative humidity and the MODTRAN derived humidity. An example of the estimation accuracy evaluation result is shown in Table I.

\section{B. Results for the Proposed Method}

Fig. 12(a) and (b) shows air temperature (a) and relative humidity (b) profiles of MODTRAN derived and the estimated by the conventional method as well as the estimated by the proposed method, respectively.

TABLE II. RMSE: ROOT MEAN SQUARE ERROR OF THE CONVENTIONAL AND THE PROPOSED METHODS FOR ESTIMATION OF AIR TEMPERATURE (T) AND RELATIVE HUMIDITY (RH) PROFILES

\begin{tabular}{|l|l|l|}
\hline Profile & Conventional & Proposed \\
\hline$(\mathrm{T})$ & $1.031(\mathrm{~K})$ & $0.607(\mathrm{~K})$ \\
\hline$(\mathrm{RH})$ & $1.779(\%)$ & $0.197(\%)$ \\
\hline
\end{tabular}




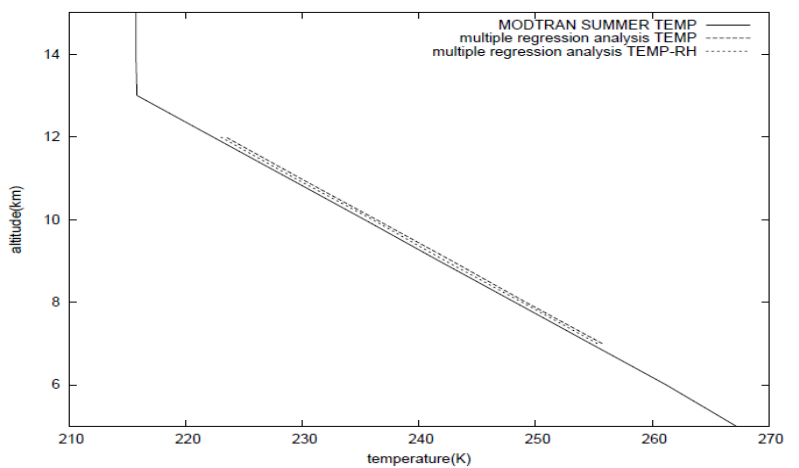

(a) Air temperature

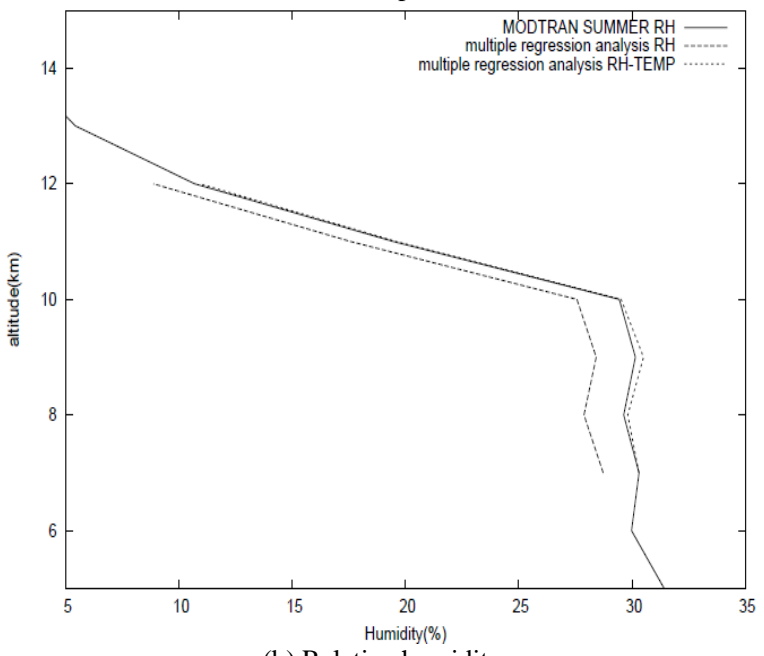

(b) Relative humidity

Fig. 12. Air temperature (a) and relative humidity (b) profiles of MODTRAN derived and the estimated by the conventional method as well as the estimated by the proposed method.

Table II shows RMSE: Root Mean Square Error of the conventional and the proposed methods for estimation of air temperature (T) and relative humidity ( $\mathrm{RH})$ profiles. It is obvious that the proposed method is superior to the conventional method by $41.4 \%$ for air temperature profile and by $88.9 \%$ for relative humidity profile.

\section{CONCLUSION}

Iteration method for simultaneous estimation of vertical profiles of air temperature and water vapor with the high spectral resolution of sounder of AQUA/AIRS data is proposed. Through a sensitivity analysis based on the proposed method for the several atmospheric models simulated by MODTRAN, it is found that the proposed method is superior to the conventional method by $41.4 \%$ for air temperature profile and by $88.9 \%$ for relative humidity profile.

Further study is highly required for another experiment with a variety of dataset and atmospheric conditions.

\section{ACKNOWLEDGMENT}

The author would like to thank Dr. Xing Ming Liang of NOAA/NESDIS and Mr. Naohisa Nakamizo of Saga University for their effort to conduct simulations and the experiments. Also, the author would like to thank all members of the fourth research group of Information Science Department of the Science and Engineering Faculty, Saga University for their valuable comments and suggestions as well as discussions.

\section{REFERENCES}

[1] Jeffrey, A.L., Elisabeth, W., and Gottfried, K., Temperature and humidity retrieval from simulated Infrared Atmospheric Sounding Interferometer(IASI) measurements, J. Geop. Res., 107, 1-11, 2002.

[2] Kohei Arai and Liang XM. Estimation of air-temperature profile with AQUA/AIRS data on the troposheric boundary, Abstract, COSPAR A1.1, A-00715, 2006.

[3] Kohei Arai and Naohisa Nakamizo, Water vapor and air-temperature profile estimation with AIRS data based on Levenberg -Marquadt, Abstract of the 50th COSPAR(Committee on Space Research/ICSU) Congress, A 3.1-0086-08,995, Montreal, Canada, July 2008

[4] Kohei Arai and XingMing Liang, sensitivity analysis for air temperature profile estimation method around the tropopause using simulated AQUA/AIRS data, Advances in Space Research, 43, 3, 845-851, 2009.

[5] Kohei Arai, Method for water vapor profile retrievals by means of minimizing difference between estimated and brightness temperature derived from AIRS data and radiative transfer model, International Journal of Advanced Computer Science and Applications, 3, 12, 145148, 2012.

[6] Rodgers, C.D., Inverse method for atmospheres: theory and practice, World Sci., Singapore, 2000.

[7] Rodgers, C.D., Information content and optimization of high spectral resolution measurements. In Optical Spectroscopic Techniques and Instrumentation for Atmospheric and Space Research II, vol. 2830, pp. 136-147, Int. Soc. For Optical Eng., Bellingham, Wash.,1996.

[8] Liou, K.N., An introduction to atmospheric radiation. Elsevier Science, USA, 2002.

\section{AUTHORS PROFILE}

Kohei Arai, He received BS, MS and PhD degrees in 1972, 1974 and 1982, respectively. He was with The Institute for Industrial Science and Technology of the University of Tokyo from April 1974 to December 1978 and also was with National Space Development Agency of Japan from January, 1979 to March, 1990. During from 1985 to 1987, he was with Canada Centre for Remote Sensing as a Post-Doctoral Fellow of National Science and Engineering Research Council of Canada. He moved to Saga University as a Professor in Department of Information Science on April 1990. He was a councilor for the Aeronautics and Space related to the Technology Committee of the Ministry of Science and Technology during from 1998 to 2000 . He was a councilor of Saga University for 2002 and 2003. He also was an executive councilor for the Remote Sensing Society of Japan for 2003 to 2005. He is an Adjunct Professor of University of Arizona, USA since 1998. He also is Vice Chairman of the Commission-A of ICSU/COSPAR since 2008. He received Science and Engineering Award of the year 2014 from the minister of the ministry of Science Education of Japan and also received the Best Paper Award of the year 2012 of IJACSA from Science and Information Organization: SAI. In 2016, he also received Vikram Sarabhai Medal of ICSU/COSPAR and also received 37 awards. He wrote 37 books and published 570 journal papers as well as 370 conference papers. He is Editor-in-Chief of International Journal of Advanced Computer Science and Applications as well as International Journal of Intelligent Systems and Applications. http://teagis.ip.is.saga-u.ac.jp/ 